\title{
Science as a service: understanding successful knowledge transfer in a New Zealand research institute
}

\author{
Moore, D*., Bayne, K. and Barnard, T. \\ New Zealand Forest Research Institute (SCION), Private Bag 3020, Sala St, New Zealand.
}

\begin{abstract}
This paper reports on an exercise conducted within a state-owned body (Crown Research Institute) in New Zealand aimed at building greater understanding of the key factors in successful research programmes. Success was defined in this study as a high level of uptake of the emerging science, with commensurate benefits to both industry and the community. The methodology had three parts. A review of the knowledge and technology transfer literature; a series of 15 semi-structured interviews with science leaders; and a facilitated workshop. The purpose of the review was to generate a robust framework upon which to centre the interview dialogues, and two models were selected. The results varied, reflecting the diversity of research services provided by the organization, but the findings were predominantly new and valuable. The importance of the long term relationship with the end users was the strongest recurring theme. The methodology may have wider application in both research and consulting settings; for the benefits derived from the interactive process with staff, as well as for the specific findings.
\end{abstract}

\section{Background}

\begin{abstract}
'It seems to me that those sciences which are not born of experience, the mother of all certainty, and which do not end in known experience ... are vain and full of error' Leonardo Da Vinci [2]
\end{abstract}

The literature holds no shortage of examples of poor communication between end users of science and the scientists. In the recent 2011 Annual Lecture of the Institute of Human Factors and Ergonomics, Peter Buckle [1] drew upon a number of studies in his call to involve the relevant parties to a greater degree in order to enhance the circle of knowledge. In particular he identifies the importance of involving those working in the field more, not only in the setting of research objectives, but also in the measurement of the impact of the resultant science in industry and society.

\subsection{Motivations and aims}

One motivation for the study reported in this paper was a desire to improve the return on research investment in a competitive market where funders are increasingly interested in the impact of science against industrial economic, environmental and socio/cultural indicators. Another was to improve job satisfaction of researchers within the organization.

The aims of this study were to: build an understanding of models of cooperation between all the various parties (end users, researchers, funders, industry bodies, etc) that had been found to be successful, and from these to generate generic principles of operation that could assist in future project planning.

\footnotetext{
* Corresponding author. dave.moore@scionresearch.com
} 


\section{Method}

A three stage method was employed. Firstly, a literature review was conducted through the National Forestry Library of New Zealand, analysis of which identified relevant concepts and models underpinning theoretical best practice in technology or knowledge transfer.

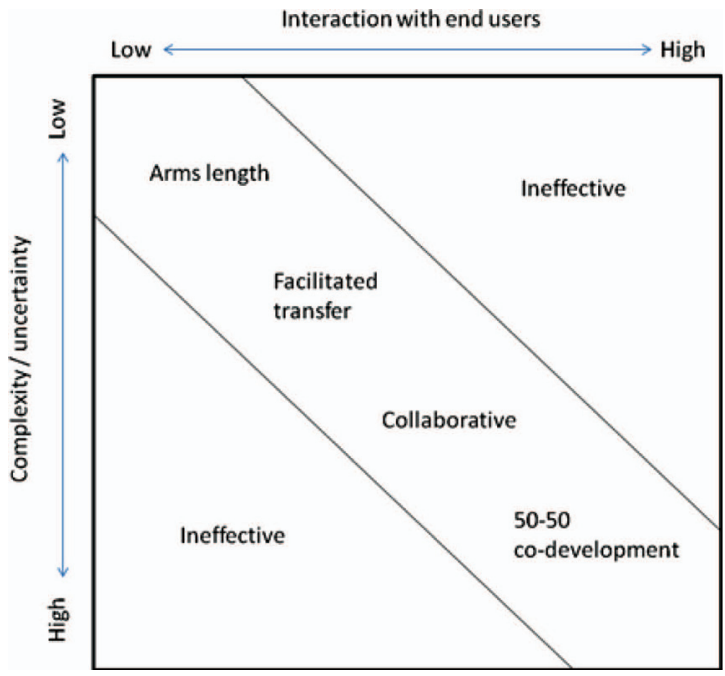

Figure 1. Appropriate matches of technology uncertainty and organizational interaction in effective technology Transfer by Stock and Tatikonda (2000)

\subsection{OIPT Model}

Figure 1. shows a model of Organisational Information Processing Theory (OIPT) applied to technology transfer. The Stock and Tatikonda model states that two constructs (task uncertainty and organisational approach) correspond to task effectiveness.

In their 2000 [3] paper, the authors place these constructs into a technology transfer (TT) context whereby task uncertainty becomes technology complexity/uncertainty; organisational approach becomes organisational interaction; and task effectiveness becomes TT effectiveness.

\subsection{A-D-E cycle}

A version of the ubiquitous analysis-designevaluation cycle [4] or spiral, used heavily in design education and user-centred R\&D was also employed to enable subjects to plot the position and role of various parties onto a project cycle template.

\subsection{Interview administration}

A semi-structured interview methodology was developed using these two models and a series of 15 individual sessions of 30 mins to an hour were conducted with scientists representing the full range of scientific and operational areas of activity within the Institute. Key factors in projects judged to be successful under the terms of the study were identified, discussed, and logged diagrammatically using the two model templates. In some cases generic patterns in recurrent failure models were also plotted by way of contrast.

The final phase of the study used a facilitated workshop to interrogate the findings by sector, and to develop interventions that could be incorporated into organizational strategy, policy and procedures.

\section{Findings}

\subsection{Method}

In the 2000 study by Stock and Tatikonda, the subjects plotted a particular project in a single position against the two axes used in Figure 1.

Interestingly, in the study reported here, the subjects instinctively used multiple plots on the graphic to plot the longitudinal development of a research and development exercise. The method is extended to tell its story over the fuller cycle. 


\subsection{Time}

Figure 2. shows a graphic from one of the set of case studies produced as a resource for the workshops.

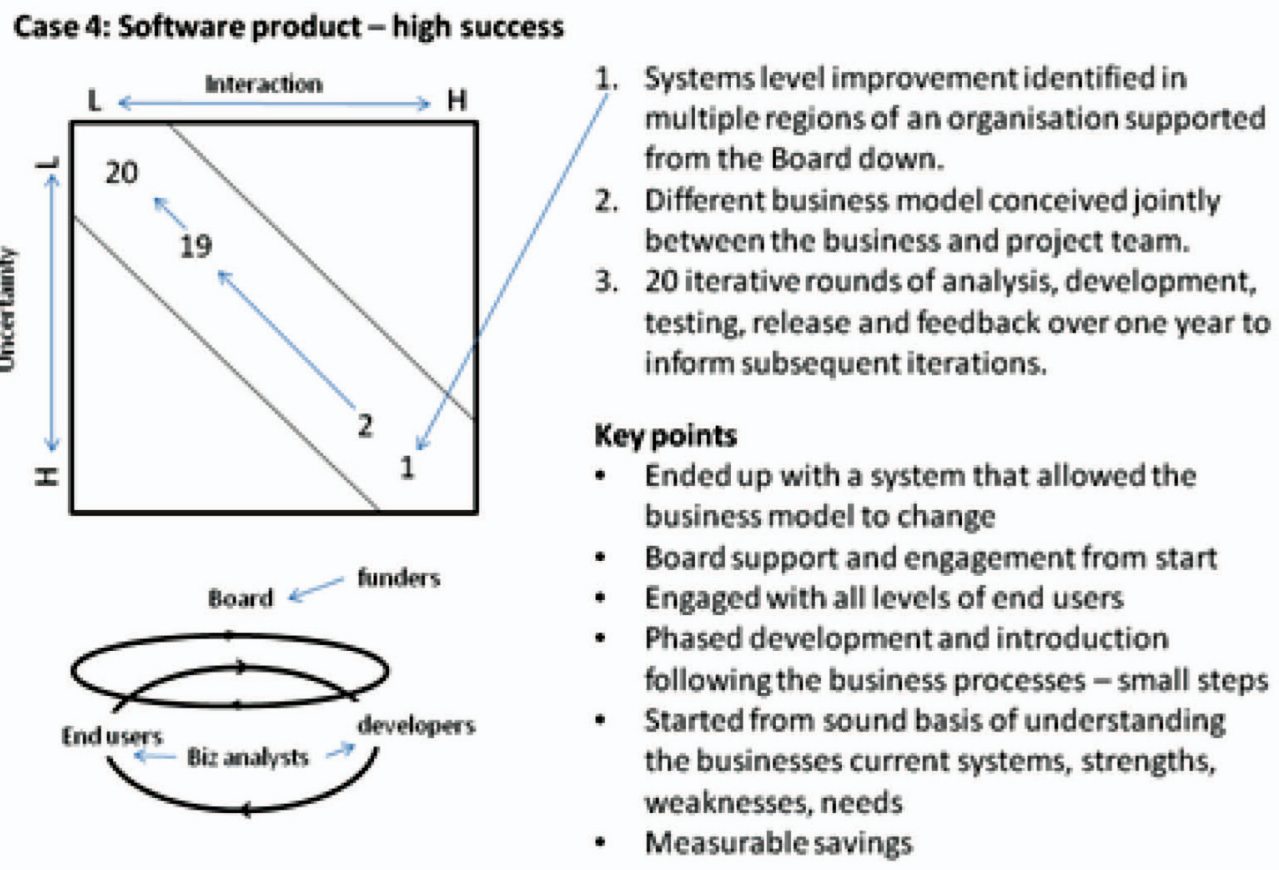

1. Systems level improvement identified in multiple regions of an organisation supported from the Board down.

2. Different business model conceived jointly between the business and project team.

3. 20 iterative rounds of analysis, development, testing, release and feedback over one year to inform subsequent iterations.

\section{Key points}

- Ended up with a system that allowed the business model to change

- Board support and engagement from start

- Engaged with all levels of end users

- Phased development and introduction following the business processes - small steps

- Started from sound basis of understanding the businesses current systems, strengths, weaknesses, needs

- Measurable savings

Figure 2. Case study showing use of the model to plot development of the project over time from iterative steps 1 to 20 
Figure 3. illustrates the use of the model in a similar way, but this time to plot the course of a technology transfer exercise that has less success. At the outset there is high uncertainty, but also low interaction with the clients / potential end users.

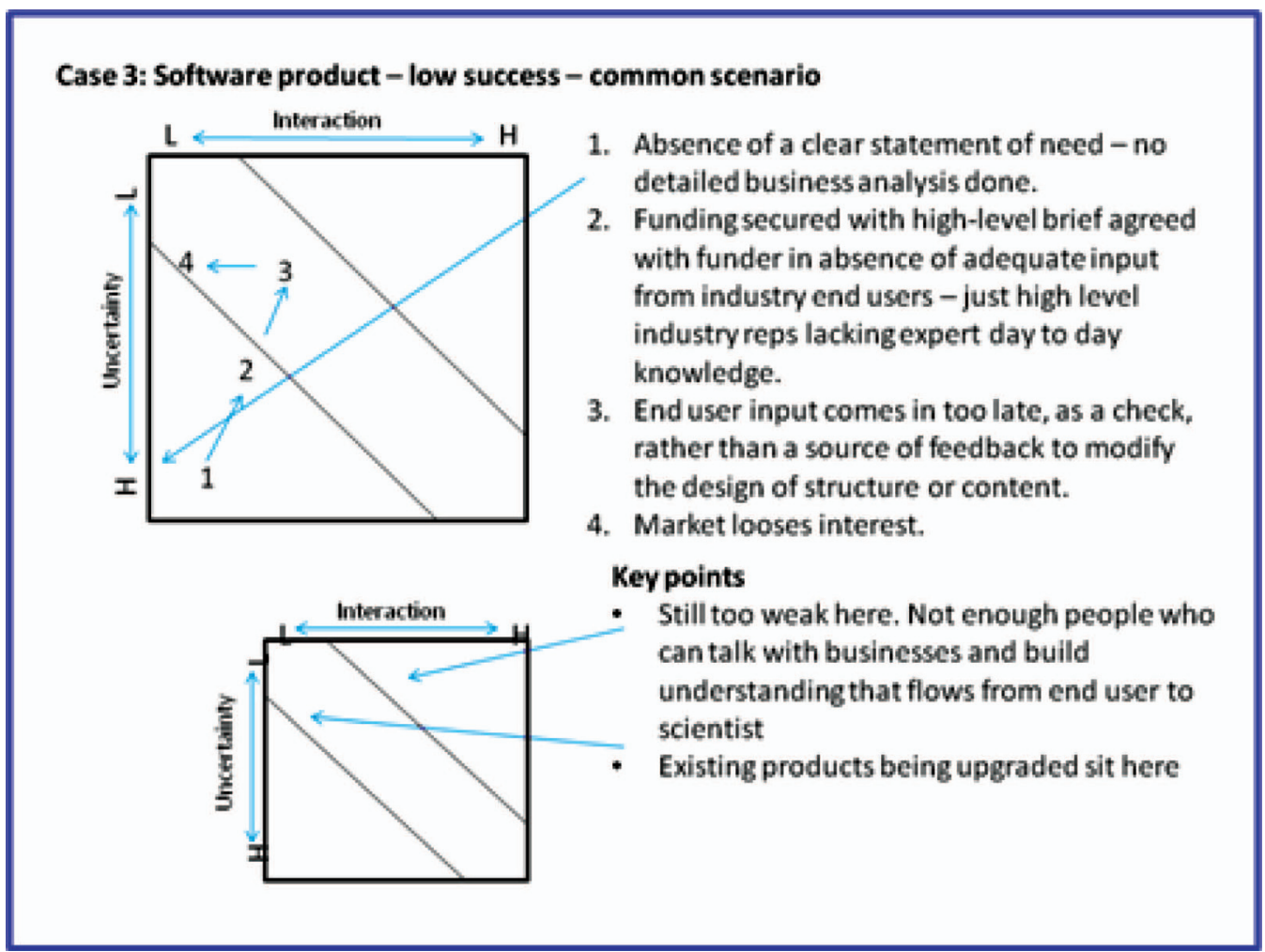

Figure 3. Case study plot with explanatory notes describing transfer process type that had been found to have low success

\subsection{Variation in transfer process types}

The study revealed a surprisingly wide range of factors, arrangements and effective transfer process types. There were significant differences between the various activity areas within the organization. The software development exercises in Figures 1 and 2 for example benefited most from care in iterative development and introduction planning.
By contrast, the consultative exercises involving indigenous communities by contrast found consultation was required to a degree exceeding that seen to be necessary in the Stock and Tatikonda cases. The most useful and interesting aspect of this study was the extended way in which the model developed by Stock and Tatikonda was used when administered with individual science leaders. The subjects automatically assumed the graphic provided the opportunity to lay out the progression of the work against the two axes from inception to completion - and in comparison to other projects. 


\section{Case 6: Soil resource and land use capability assessment for local Maori land owners}

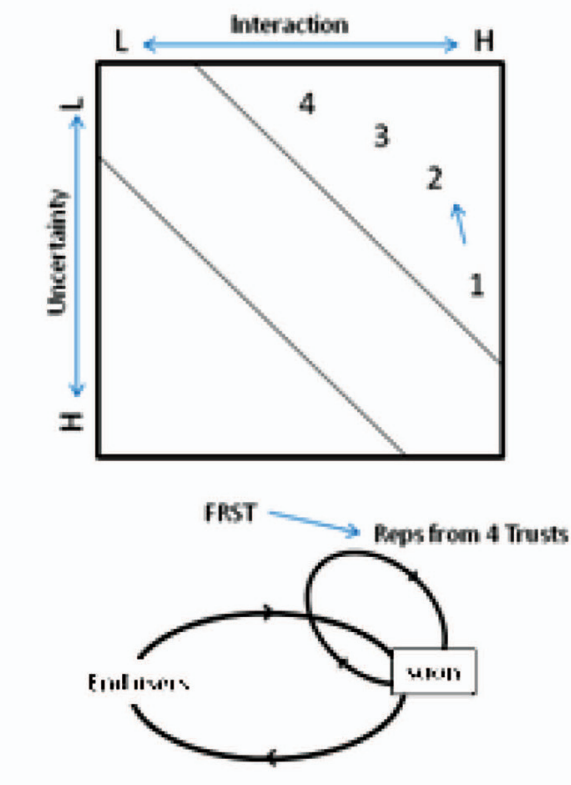

1. Work with a group of 4 Maori Trusts on a soil resource and land use capability assessment. Aim of increașing economic return without adverse environmental effects

2. The exercise called for a close relationship to be established first. Didn't want 'another govt report churned out for us without consultation'

3. Slow careful build up to field work. Workshops and interviews to gather data on priorities, values and level of tech knowledge regarding soil

4. Workshops held to explain and impart a deeper understanding of the findings

\section{Key points}

- Trust and understanding built before detailed needs analysis performed

- Transfer planned and measured

- Weaknesses: subsequent loss of communication and chances to evaluate impact

Figure 4. Case Study showing a different successful track of plots

\section{Conclusions}

The exercise reported in this paper generated valuable understanding of organization-specific and intraorganisational best practice in technology and knowledge transfer; not just from scientist to enduser, but critically also from end users to the researchers.

Most notably the vital function of relationship building was identified. The additional time spent in building establishing trust and gaining the active cooperation of bodies and individuals with key roles as intermediaries for intervention design and implementation was found in most cases to be vital investment. Without the engagement of change agents in the processes excellent science remained under-applied.
The specific learnings are probably of interest to similar bodies, and the methodology appears to have merit for wider application. There is also potential we believe based on discussions at the workshops, to use a series of these graphics in line, with overlaps or gaps between, to explore the actions and successes of organisations in maintaining and creating opportunities not just during, but also between contracts. 


\section{References}

1. Buckle, Peter (2011) "The perfect is the enemy of the good' - ergonomics research and practice. Institute of Ergonomics and $\mathrm{Hu}$ man Factors Annual Lecture 2010', Ergonomics, 54: 1, $1-11$

2. Da Vinci, Leonardo. From: Trattatto della Pittura, 33. Cited in: Barber, B. (Ed) (1970). L.J Henderson on the social system. Heritage of Sociology series. University of Chicago Press. Page 78

3. Stock. G.T., Tatikonda, M. V. (2000). A typology of project-level technology transfer processes. Journal of Operations Management 18(6): 719-737.

4. van den Akker, J. (1999). Chapter One: Principles and Methods of Development Research. In: Design Approaches and Tools in Education and Training. Eds: van den Akkers, J., Branch, M., Gustafson, K., Nieveen, N. \& Plomp, T. Published by Kluwer, Netherlands. 